\title{
ATUAÇÃO DA ENFERMEIRA NA ASSISTÊNCIA À MULHER NO PROCESSO DE PARTURIÇÃO' ${ }^{1}$ \\ PRACTICE OF THE NURSE THAT GIVES ASSISTANCE TO WOMEN IN THE PROCESS OF DELIVERY

\author{
ACTUACIÓN DE LA ENFERMERA QUE ASISTE A LA MUJER EN EL PROCESO DEL PARTO
}

\author{
Lena Maria Barros², Raimunda Magalhães da Silva
}

\footnotetext{
${ }^{1}$ Artigo extraído da Dissertação de Mestrado intitulada "Parto normal: significado e atuação da enfermeira". Programa de PósGraduação em Enfermagem/UFC.

${ }^{2}$ Enfermeira. Mestre em Enfermagem pela Universidade Federal de Fortaleza (UFC). Docente da Universidade Federal do Maranhão. Pesquisadora do Núcleo de Pesquisa em Enfermagem (NUPEn).

${ }^{3}$ Enfermeira. Doutora em Enfermagem. Docente da Universidade de Fortaleza (UNIFOR). Colaboradora da Pós-Graduação na Universidade Federal do Ceará (UFC). Pesquisadora do CNPq. Orientadora da Dissertação.
}

\section{PALAVRAS-CHAVE:}

Parto normal.

Relações enfermeira-paciente.

Enfermagem obstétrica.
RESUMO: Nosso objetivo neste trabalho foi conhecer a atuação da enfermeira de centro obstétrico na assistência à mulher no processo de parturição. É um estudo de campo do tipo descritivo, realizado em quatro maternidades públicas de São Luís - MA, de abril a julho de 2002, após consentimento dos sujeitos, respeitando os aspectos éticos. Participaram do estudo, 21 enfermeiras de Centro Obstétrico. O agrupamento das falas feito pela técnica de Análise de Conteúdo, possibilitou a organização da categoria "atuação da enfermeira na assistência à mulher no processo de parturição" com as sub-categorias: assistência temporal na trajetória do nascimento e maneira de cuidar na trajetória natural do nascimento. Ao término do estudo, evidenciamos que a enfermeira de centro obstétrico atua junto a mulher com ações diretas e passivas (observando, protegendo); indiretas (administrando) e com participação mais efetiva, tomando decisões e influenciando a ação e o comportamento desta (oferecendo cuidado solidário e obstétrico).

\section{KEYWORDS:}

Normal childbirth. Nurse-patient relationships. Obstetric nursing.

\section{PALABRAS CLAVE:}

Parto normal.

Relaciones enfermera-paciente.

Enfermería obstétrica.

\begin{abstract}
Our objective in this study was to know the practice of the nurse in the obstetrics center in the assistance to women during the delivery process. It is a descriptive field study conducted at four public maternities of São Luís - Ma, Brazil, from April to July of 2002, with the consent of the subjects, respecting the ethical aspects. Twenty-one nurses at the obstetrics center participated in the study. The grouping of the conversations made by the Content Technique, made the organization of the category "the practice of the nurse in the assistance to women during the delivery process" and its sub-categories: temporal assistance of the birth trajectory and the method of care during the natural birth trajectory possible. At the end of the study, we prove that the nurse of the obstetric center acts together with the woman with direct and passive actions (observing, protecting); indirect actions (administrative) and with more effective participation making decisions and influencing the action and the behavior of this woman (offering solidary and obstetric care).
\end{abstract}

RESUMEN: Nuestro objetivo en el presente trabajo fue conocer la acción de la enfermera del centro obstétrico en el momento del parto en lo que se refiere a la ayuda y amparo a la mujer que da a luz. Es un estudio de campo del tipo descriptivo, llevado a cabo en cuatro maternidades públicas de São Luís - Maranhão, de abril a julio de 2002, con el debido consentimiento de los inmiscuidos, respetando los aspectos éticos. Participaron del estudio, 21 enfermeras del Centro Obstétrico. La coletanea de testimonios realizado por la técnica de Análisis de Contenido, posibilitó la organización de la categoria "acción de la enfermera en la ayuda y amparo a la mujer durante el proceso de dar a luz", con las categorias derivadas de "amparo temporal en la trayectória del nacimiento y modo de cuidar en la trayectória natural del nacimiento". Al finalizar el estudio, evidenciamos que la enfermera del centro obstétrico actúa lado a lado con la mujer con acciones directas y pasivas (observando, protegiendo); indirectas (administrando) y con la participación más efectiva, tomando decisiones e influyendo en la acción y el comportamiento de la misma (ofreciendo cuidados solidarios y obstétricos).

Endereço:

Lena Maria Barros

Rua U, quadra 10, 21, residencial Boa Morada

65070501 - Recanto dos Vinhais, São Luís, MA

E-mail lenafonsecamaria@ibest.com.br
Artigo original: Pesquisa

Recebido em: 15 de fevereiro de 2004

Aprovação final: 24 de junho de 2004 


\section{INTRODUÇÃO}

A atuação da enfermeira na assistência à mulher no processo de parturição, atualmente, é considerada como uma possibilidade para a redução da morbimortalidade materna e perinatal. Com essa assistência, poderá diminuir as ações intervencionistas do tipo cesarianas, muitas vezes desnecessárias. Também poderá privilegiar majoritariamente a parturiente como ser ativo no referido processo, conduzido por uma assistência mais humanizada.

Tais prerrogativas levaram o Ministério da Saúde a tomar medidas para alcançar esse objetivo, criando a portaria n. ${ }^{\circ} 163 / 98$, que introduz no SIH/SUS a remuneração da assistência ao parto realizado por enfermeira obstetra e limitação de valores pagos para o parto cesariano, visando incentivar o parto normal humanizado e reduzir o número de partos cirúrgicos. Esse procedimento é considerado fator de mortalidade materna quando realizado fora das condições específicas ${ }^{1}$.

O número de enfermeiras obstetras atuando no país ainda é muito baixo e, conseqüentemente, o número de partos realizados por esse profissional representa $0,9 \%$ do total de partos realizado pelo SUS, embora estime-se que o número real de partos seja bem maior ${ }^{2}$.

Em São Luís -MA foi constatado na pesquisa "Avaliação da qualidade de maternidades", realizada em 2000, que de todos os partos ocorridos, 25,7\% foram cesarianas e $76,4 \%$ normais e, destes, somente $0,3 \%$ foram realizados por enfermeira, enquanto $4,1 \%$ foi realizado por parteira, 29,3\% por auxiliar de enfermagem e 60,3\% por médicos ${ }^{3}$. Este trabalho comprovou que a atuação da enfermeira na realização do parto é quase nula.

Durante nossa prática obstétrica, ao acompanhar alunos de graduação e de pós-graduação nas maternidades, observamos o envolvimento pouco expressivo das enfermeiras na assistência à parturiente $\mathrm{e}$ ao parto. Ressaltamos, entretanto, que nossa permanência e nosso cuidado com as gestantes e parturientes, fazem com que as mesmas sintam-se mais seguras e confiantes em relação à sua trajetória da gestação e da parturição.

O grande paradoxo entre a necessidade da assistência prestada pela enfermeira à mulher no processo de parturição e sua participação pouco perceptível, aumentou nossa inquietação em desvendar os verdadeiros motivos de tal comportamento, mesmo estando em evidência todo amparo legal visualizado a partir da década de 60, em que a assistência em obstetrícia, pela enfermeira, passou a ser uma realidade instituída legalmente 4 .

Atualmente, as perspectivas para a enfermeira conquistar no âmbito da obstetrícia, seu espaço profissional, de forma ética e legal, aumentaram, com a Resolução do MS/COFEN - 223/99, que dispõe sobre a atuação de enfermeiros na assistência à mulher no ciclo gravídico puerperal, ficando assim sua competência ${ }^{5}$ :

- realização do parto normal sem distócia;

- assistência à gestante, parturiente e puérpera;

- acompanhamento da evolução e do trabalho de parto;

- execução e assistência obstétrica em situação de emergência;

- assistência à parturiente e ao parto normal;

- identificação das distócias obstétricas e tomada de todas as providências necessárias, até a chegada do médico, devendo intervir, de conformidade com sua capacitação técnica - científica, adotando os procedimentos que entender imprescindíveis, para garantir a segurança do binômio mãe / filho;

- realização de episiotomia, episiorrafia e aplicação de anestesia local, quando couber;

- emissão do Laudo de Enfermagem para Autorização de Internação Hospitalar, constante do anexo da Portaria SAS/MS - 163/98, acompanhamento da cliente sob seus cuidados, da internação até à alta.

Diante das possibilidades éticas e legais, a enfermeira tem ampla atuação no acompanhamento do processo do parto e nascimento; no entanto, observamos uma lacuna nessa atuação. Assim, na perspectiva de suscitar nas enfermeiras a necessidade social, política e ética de uma atuação mais efetiva e mais consciente para uma assistência de qualidade à mulher no processo de parturição, o nosso objetivo neste estudo é: conhecer a atuação da enfermeira de centro obstétrico, na assistência à mulher, no processo de parturição.

\section{METODOLOGIA}

Trata-se de uma pesquisa de campo do tipo descritiva, desenvolvida em cenário "natural" de atuação das enfermeiras. O estudo foi realizado em qua- 
tro maternidades públicas de São Luís - MA, as quais foram denominadas pelas letras A, B, C e D. Participaram 21 enfermeiras que atuam em centro obstétrico, para as quais foi apresentado o termo de consentimento e esclarecidos todos os aspectos éticos pertinentes à pesquisa respeitando as recomendações da Resolução do Conselho Nacional de Saúde no 196/ $96^{6} \mathrm{e}$ com o intuito de garantir o anonimato, as enfermeiras receberam nomes fictícios no relatório final.

Após ter sido aprovado o projeto de pesquisa, pelo Comitê de Ética em Pesquisa do Hospital Universitário da Universidade Federal do Maranhão (HU - UFMA), foi solicitado aos diretores e chefes de serviço de enfermagem das maternidades, a autorização para realização da pesquisa. Os dados foram coletados no período de abril a julho de 2002, por meio de entrevista semi-estruturada, utilizando-se do gravador e questões norteadoras sobre a temática, para favorecer o diálogo no sentido de aprofundar o conhecimento sobre a temática.

Os resultados foram organizados de acordo com a técnica de Análise de Conteúdo que é "um conjunto de técnica de análise das comunicações, que utiliza procedimentos sistemáticos e objetivos de descrição do conteúdo das mensagens" ". Conduzimos o processo percorrendo várias etapas a iniciar com leitura globalizada do material, passando por recortes em suas partes, para serem categorizadas e classificadas, visando uma decodificação do significado das partes em correlação com o todo. Buscamos descobrir os núcleos de sentido que compõe uma comunicação, cuja presença ou freqüência guarda alguma relação com o objetivo visado ${ }^{8}$.

\section{RESULTADOS}

A maioria das participantes mostrou satisfação e interesse em colaborar, não só falando sobre seu objeto de interesse para a efetivação da pesquisa, mas também como "desabafo" de suas inquietações do seu cotidiano profissional, especialmente as enfermeiras obstétricas. Algumas ficaram indecisas e inseguras sobre o que iriam responder julgando não estarem preparadas ou talvez que suas falas não estivessem adequadas ao tema. Umas desviaram do cerne da questão, e isso pode ter origem na maneira dessas enfermeiras prestar cuidados à mulher na trajetória do nascimento, o que veio direcionar sobremaneira suas respostas, outras emitiram respostas curtas e outras mais longas e bem elaboradas. Obtivemos também respostas dadas com a maior convicção, com a "alma", com o sentimento de quem vivencia e se envolve no que faz; outras, de uma forma mais superficial, técnica, com certa frieza e distante.

Todas eram do sexo feminino, a maioria, especialista em enfermagem obstétrica pela UFMA, casada e com mais de cinco anos de graduação e trabalhando há mais de quatro anos em centro obstétrico. A faixa etária variou entre 25 a 57 anos, com predominância das faixas etárias de 25 a 34 anos e 40 a 49 anos.

Ao se buscar sua história obstétrica, detectamos que dez eram nulíparas e onze tiveram de uma a três gravidezes; nove foram submetidas a parto cesariano e somente duas tiveram partos normais (uma teve três e a outra dois partos normais).

A análise das falas, de acordo com a técnica já mencionada, originou a temática descrita a seguir, denominada de: "atuação da enfermeira na assistência à mulher no processo de parturição".

No percurso das entrevistas, notou-se que as enfermeiras atuam, quer de forma direta, cuidando da parturiente, quer de forma indireta, proporcionando meios para um cuidar mais qualificado e humanizado. Essa atuação pode ser entendida a priori como um conjunto de ações traduzidas no "fazer" e no "cuidar", expressando o objetivo maior da enfermagem, durante as etapas de doação materna (parir) e do desabrochar da vida (nascer).

Dessa forma, a referida temática foi desdobrada nas sub-temáticas: assistência temporal na trajetória do nascimento e maneira de cuidar na trajetória natural do nascimento.

$\mathrm{Na}$ assistência temporal na trajetória do nascimento percebe-se a assistência temporal como uma experiência vivenciada pela enfermeira, de curta duração, tanto em relação ao passado como em direção ao futuro, ou seja, no pré-natal, parto e puerpério. A temporalidade consiste em experienciar o tempo, sendo esta a vivência que mais próxima se encontra de nosso existir?

Para melhor compreensão da indiscutível importância da assistência da enfermeira à gestante no ciclo gravídico-puerperal, a assistência temporal foi desdobrada, de acordo com o momento em que ela ocorre, ou seja: acompanhando a gravidez e o trabalho de parto; acompanhando o parto e em atividades administrativas. As falas a seguir, correspondem ao acompanhamento da gravidez e ao trabalho de parto. 
[....] a assistência começa no pré-natal para que a mulher possa ter um parto normal[..] (Sila).

A assistência que a enfermeira dá no parto normal é muito importante, porque ela dá assistência no momento da admissão, no pré-parto, no parto, no pós-parto e também ao recém-nascido (Ceiça).

A gente procura acompanhar a evolução desse trabalho de parto até a chegada na sala de parto (Violeta).

A assistência da enfermeira no acompanhamento da mulher no ciclo gravídico-puerperal tem apresentado resultados satisfatórios na redução da morbimortalidade materna e perinatal. Vários trabalhos mostram essa realidade, como o resultado da pesquisa realizada por Goldman e Barros (1998), em São Paulo, com 178 parturientes assistidas exclusivamente por enfermeiras obstétricas, onde $80 \%$ delas não apresentaram nenhuma intercorrência obstétrica ou clínica ${ }^{10}$.

As habilidades práticas e humanizadas da enfermeira permitem detectar e corrigir precocemente qualquer intercorrência e/ou desvio do mecanismo fisiológico da gestação possibilitando melhor qualidade na assistência ao parto e ao nascimento. Verificamos que assistir denota uma ação mais passiva de observar, acompanhar, favorecer e assistência como auxílio, proteção. $\mathrm{Na}$ realidade, a idéia passada pelas entrevistadas, sobre suas práticas, condiz perfeitamente com a idéia no sentido da assistência que caracteriza um cuidar passivo, muitas vezes indiferente, mecânico e impessoal ${ }^{11}$.

A interação efetiva entre a mulher e os profissionais de saúde desde o pré-natal, no trabalho de parto e no parto, contribui para aliviar a ansiedade, superar dúvidas e temores, aumentar a segurança com relação ao parto. É importante que a mulher gestante resgate a autoconfiança em relação à capacidade natural de seu corpo, enquanto parturiente. Vale ressaltar a influencia do ambiente hospitalar pouco acolhedor, estressante, desconhecido, associado a uma assistência inadequada motivada por inúmeros fatores ${ }^{12}$.

Com relação ao acompanhamento do parto, as falas deixam claro que um acompanhamento humanizado, ou seja, aquele executado de forma contínua e segura, com a permanência da enfermeira, no trabalho de parto, com vigilância constante e duradoura, respeito à parturiente, influencia não só a opção da gestante pelo parto normal como a torna mais colaboradora e segura no momento do parto.

Quando tem uma mulher e eu sei que o parto vai ser normal, acompanho, vou para sala[...] porque elas ficam muito apegadas, porque geralmente a enfermeira é aquela que está ali, dizendo: 'vai mãe, faz a força comprida', e talvez até pelo lado bumano da gente, ela diz: 'me ajuda'! outras dizem: 'minha colega'! Aquele jeito, aquela coisa bem intima (Régia).

A fragilidade da parturiente enquanto cliente faz com que ela espere encontrar na enfermeira que a assiste, uma pessoa forte e ao mesmo tempo, sensível, que possa acolhê-la e ampará-la na dor, subseqüentemente num trabalho de parto que tanto pode ser laborioso quanto rápido e sem intercorrências ${ }^{13}$.

Apreendemos, também, que a atuação da enfermeira se dá de forma indireta com ações administrativas do centro obstétrico, no sentido de garantir condições materiais e recursos humanos para uma efetiva execução dos procedimentos. Em todas as etapas do processo de parturição, administrar a assistência é o que parece ser a forma mais freqüente de atuação da enfermeira, nas maternidades públicas de São Luís e que absorve o maior tempo e dedicação no serviço.

Dentre as funções administrativas abordadas destacam-se: supervisão do pessoal de enfermagem, da assistência prestada à clientela; provimento e controle do material para a execução dos serviços de enfermagem e médico, além de coordenação do centro obstétrico.

[...] nosso trabalho aqui, está mais direcionado com relação a parte administrativa do centro obstétrico, não deixando faltar material, ver se a quantidade de pessoal é suficiente e ver como estão ocorrendo os procedimentos (Sâmara).

Além das atribuições já mencionadas, existem as funções de caráter burocrático, em que a enfermeira assume toda responsabilidade, e que passam a preencher grande parte do seu tempo disponível, associado à deficiência de pessoal de enfermagem em relação a outros profissionais e a demanda de trabalho, dificultando, desse modo a atuação direta da enfermeira à mulher no trabalho de parto e parto, como é expresso na fala a seguir:

[...] na realidade a gente não chega perto quando a paciente está parindo, porque é só uma enfermeira por plantão noturno e dá mal para se fazer as burocracias e dar uma certa assistência para aquelas pacientes que estão com problemas (Tiane).

Com relação às funções administrativas, a supervisão, foi a atividade mais destacada pelas entrevistadas. $\mathrm{E}$ no contexto do sistema de saúde vigente, essa atividade da enfermeira ainda representa a prioridade para muitas instituições de saúde ao contratarem os serviços das enfermeiras em nome da qualidade e 
operacionalização dos serviços, quer no sentido da produtividade ou da prestação de uma assistência eficaz. Embora sendo uma necessidade premente nos serviços de saúde, não se pode perder de vista o objeto da ação da enfermeira, "o cuidar," e comprometer a qualidade da assistência de enfermagem.

Na enfermagem, são poucos os enfermeiros que não desenvolvem a função de supervisão, desde os que prestam cuidados diretos aos pacientes até os que chefiam divisões ou serviços de enfermagem, em maior ou menor complexidade ${ }^{14}$.

Os dados da pesquisa estão condizentes com os relatos da autora referida anteriormente, uma vez que grande parte das enfermeiras destacou a função de administração (supervisão ou coordenação) como a atividade principal assumida nas instituições que atuam, mesmo aquelas que têm qualificação na área obstétrica.

A sub-categoria maneira de cuidar na trajetória natural do nascimento, será analisada como um processo interativo entre a enfermeira (cuidadora) e a parturiente (ser cuidado), onde a primeira tem um papel ativo desenvolvendo ações e comportamentos de cuidar e a parturiente tem um papel mais passivo e de múltiplas aprendizagens. Este última é estimulada a contribuir no cuidado, a partir dos ensinamentos da enfermeira e dos demais membros da equipe de saúde, para ser responsável pelo próprio cuidado e de seu filho.

Processo de cuidar é entendido como o desenvolvimento de ações, atitudes e comportamentos com base em conhecimento científico, experiência, intuição e pensamento crítico, realizado para e com a paciente/ cliente/no sentido de promover, manter e/ou recuperar sua dignidade e totalidade humana. Por isso, esse processo envolve crescimento ${ }^{11}$.

Para favorecer a compreensão da atuação das enfermeiras na assistência à mulher no processo de parturição, procuramos extrair das falas das entrevistadas, termos semelhantes que evidenciaram objetividade, lógica e clareza do fazer profissional da enfermeira, na tarefa de acompanhar a mulher, no modelo institucional vigente. Isto nos permitiu a construção dos seguintes agrupamentos: demonstrando compreensão, respeito e solidariedade; fornecendo apoio, orientação e incentivo; monitorando o trabalho de parto e o parto com humanização; realizando o parto e os cuidados ao recém-nascido.

Esses agrupamentos originaram dois tipos de cuidados que foram classificados em cuidados solidários, que corresponde aos dois primeiros, e cuidados obstétricos, que compreende os dois últimos ${ }^{15}$.

As falas a seguir, correspondem ao primeiro agrupamento, cujas idéias emergiram das experiências e vivências das entrevistadas ao lidar com a mulher durante o processo de parir.

Atuo ajudando a mulher a aumentar sua auto confiança e auto estima onde só ela pode parir, os outros estão ali para ajudá-la (Arlea).

$A$ assistência ao parto normal, antes de tudo, eu vejo como respeito àquela mulher que é igual a nós, só porque foi descaracterizada, pois tiraram dela as jóias, o penteado do cabelo, o batom, tiraram tudo dela, até o nome. A gente sabe que elas vão passar por um processo que infelizmente acaba sendo estressante (Neri).

Este agrupamento mostra uma postura de aproximação e valorização do ser cuidado (parturiente, como ser consciente, ativo, sensível, que necessita de cuidados que promovam não só sua integridade física mas, sobretudo, sua dignidade e auto-estima, considerando seus sentimentos e sua individualidade. Evidenciamos, também, que a maneira de cuidar da enfermeira tem sido contextualizada sob o enfoque do cuidar humanizado. ${ }^{16}$ Esse cuidado que reflete a concepção de qualidade, onde o cuidador é percebido como uma presença dinâmica, capaz de acolher, refletir, reconhecer e desempenhar, com competência e sensibilidade; uma assistência voltada às necessidades dos indivíduos ou grupos populacionais.

As falas a seguir, vêm reforçar o conhecimento existente de que as ações educativas, de incentivo e de apoio, são elementos imprescindíveis e arraigados no cotidiano da enfermeira em qualquer área de atuação e em obstetrícia, no processo de parturição, torna-se imprescindível dada a realidade constatada em que a assistência à mulher no ciclo gravídico puerperal ainda é feita de forma generalizada e impessoal, por não representar uma prioridade no contexto geral da maioria das instituições.

Faço orientação no pré-parto, principalmente na evolução do parto, na posição, na ação contrátil do útero, do que elas vão sentir na sala de parto e sobre a necessidade do aleitamento materno exclusivo (Brana).

No pré-parto eu incentivo as mulheres para que venham parir de forma natural, mostrando a importância principalmente na recuperação que é mais rápida e a facilidade no manejo da criança dentro do alojamento conjunto (Andyra).

Converso, compartilhando de suas angústias, de suas preocupações, procuro distrai-la com assuntos que elas gos- 
tam de ouvir como o nome e o sexo do bebê, que o bebê está sendo esperado pela equipe, com muita alegria[...] (Arlea).

Em alguns depoimentos percebeu-se que a maneira de cuidar das enfermeiras na trajetória do nascimento é exercida também com o monitoramento do trabalho de parto e do parto com humanização, como uma forma de minimizar ou de superar os sentimentos negativos, as concepções preconcebidas e experiências difíceis vivenciadas, relacionados ao parto normal, manifestados por elas e ao mesmo tempo conquistar a confiança e elevar sua auto-estima.

[...] faço algum exercício com ela, até chegar o momento de ir para a sala de parto, assim como o acompanhamento dos batimentos cárdio-fetal (Osana).

Ajudo massageando as costas, pegando na mão, oferecendo água ou algum líquido, proporcionando a troca de experiência com outras mulheres, as vezes permitindo a aproximação de algum familiar, faço toque vaginal, dinâmica uterina, controle dos sinais vitais, digo pra ela ficar na posição mais confortável na hora da contração, encaminho para o banho de chuveiro. Na hora do parto explico que a força só é feita na hora da contração, ponho as pernas e as mãos na posição (Arlea).

O processo de parturição é uma etapa da vida da mulher que acarreta profundas e significativas mudanças fisiológicas e psicológicas na parturiente, no recém-nascido e familiar, deixando saldos positivos e/ou negativos irreversíveis. O cuidado prestado pela enfermeira e outros profissionais de saúde, podem modificar ou amenizar as atitudes negativas manifestadas pela mulher nesse percurso, facilitando o transcorrer fisiológico do processo. Além disso, pode significar uma oportunidade para os profissionais exercitarem suas habilidades técnica, científica e humanística no sentido de proporcionar um parir e um nascimento saudáveis.

\section{CONSIDERAÇÕES FINAIS}

Refletindo o contexto geral do trabalho, buscamos a caracterização das enfermeiras de centro obstétrico e as diversas formas de atuação destas, frente a assistência à mulher no processo de parturição, que se encontravam subjacentes em seus depoimentos, utilizando a técnica de Análise de Conteúdo. Pudemos então extrair a temática "atuação da enfermeira na assistência à mulher no processo de parturição", e as sub-temáticas: assistência temporal na trajetória do nascimento e maneira de cuidar na trajetória natural do nascimento.
$\mathrm{Na}$ assistência temporal na trajetória do nascimento foram demonstradas ações diretas e indiretas desempenhadas com a parturiente. Denominamos de ações diretas: o acompanhamento à parturiente, a observação, o auxílio e a proteção, durante o trabalho de parto e o parto. Apesar de serem atuações diretas, são feitas de forma passiva. Chamamos de indiretas as ações administrativas onde as enfermeiras atuam fornecendo condições para que outros profissionais executem a assistência.

$\mathrm{Na}$ maneira de cuidar na trajetória natural do nascimento, percebemos a atuação da enfermeira com uma participação mais efetiva junto a parturiente, tomando atitude e influenciando a ação e o comportamento desta. Este significado foi desdobrado em cuidado solidário, ou seja, quando ao prestar cuidados, a enfermeira demonstra compreensão, respeito, solidariedade; fornece apoio, orientação e incentivo. Chamamos de cuidado obstétrico propriamente dito quando presta cuidado monitorando o trabalho de parto e o parto, ou realiza o parto.

Evidenciamos ainda que, por imposição das rotinas institucionais, a enfermeira envolve-se com atividades administrativas, que absorvem a maior parte de seu tempo, além das burocráticas, que a instituição julga ser de competência única e exclusiva da enfermeira.

No decorrer da entrevista e nos momentos de conversas informais, percebemos que a enfermeira reconhece que sua atuação é de extrema importância e sente necessidade do contato direto com a mulher, a fim de conhecer sua história de vida e identificar as necessidades individuais de cada uma, e com isso prestar uma assistência oportuna e de melhor qualidade.

\section{REFERÊNCIAS}

1 Ministério da Saúde (BR). Seminário Nacional Assistência Obstétrica no Brasil. Desafios e estratégias para ação. Brasília: O Ministério; 1999.

2 Secretaria de Políticas de Saúde (BR). Área Técnica de Saúde da Mulher. Parto, aborto e puerpério: assistência humanizada à mulher. Brasília: A Secretaria; 2001.

3 Santos GMB dos, et al. Aspectos da assistência hospitalar ao parto. In: Alves MTSSB, Silva AAM da, organizadores. Avaliação de qualidade de maternidades. São Luís: UFMA: Sec. de Estado da Saúde, UNICEF; 2000. p.33-46.

4 Maranhão AMSA, et al. Atividades da enfermeira obstetra no ciclo gravídico-puerperal. São Paulo: EPU; 1990.

5 Conselho Federal de Enfermagem (BR). Resolução 223/99. 
Rio de Janeiro.[online] [citado 2001 Set 20]. Disponível em: URL: http://www.portalcofen.gov.br/legislacao/r223.htm. Acesso em: 20 set. 2001.

6 Conselho Nacional de Saúde BR). Resolução no 196/ 96. Decreto $n^{\circ} 93.933$ de janeiro de 1987. Estabelece critérios sobre pesquisas envolvendo seres humanos. Brasília: O Conselho; 1996.

7 Bardin L. Análise de conteúdo. 70ª ed. Lisboa: Persona; 1977

8 Rodrigues MSP, Leopardi MT. O método de análise de conteúdo: uma versão para enfermeiros. Fortaleza: Fundação Cearense de Pesquisa e Cultura; 1999.

9 Forghieri YC. Psicologia fenomenológica: fundamentos, método e pesquisa. São Paulo: Pioneira; 1993.

10 Goldmann RE, Barros SMO. Análise da assistência do trabalho de parto e parto realizado por enfermeiras obstetras. Acta Paul Enferm 1998 Jan-Abr;11(1):21-9.
11 Waldow VR. Cuidado humano: o resgate necessário. $3^{\text {a ed. }}$ Porto Alegre: Sagra Luzzatto; 2001.

12 Cechin PL. Reflexões sobre o resgate do parto natural na era da tecnologia. Rev Bras Enferm 2002 Jul-Ago; 55(4): 444-8.

13 Soares BA. As emoções da enfermeira na assistência a parturientes. Nursing 2001 Jun; 37:25-9.

14 Cunha K de C. Supervisão em enfermagem. In: Kurcgant $\mathrm{P}$, organizadora. Administração em enfermagem. São Paulo: EPU; 1991.

15 Collaço VS. Parto vertical: vivência do casal na dimensão cultural do processo de parir. Florianópolis: Cidade Futura; 2002.

16. Frota MLM. Enfermagem obstétrica: o cuidar e o ensino na perspeciva da assistência humanizada. In: Ochoa AP, coordenadora. Anais do $52^{\circ}$ Congresso Brasileiro de Enfermagem; 2000 Out 21-26; Recife, Brasil. Recife: ABEn - PE; 2000. p. 179 - 184. 